\title{
A DIVERSIDADE DA CULTURA FRONTEIRIÇA A OESTE DA PROVÍNCIA DO RIO GRANDE DE SÃO PEDRO: O COMÉRCIO E A PARÓQUIA DE SÃO PATRÍCIO DE ITAQUI (1850-1870)'
}

\author{
DIVERSITY OF CULTURE BORDER WEST OF THE \\ PROVINCE OF RIO GRANDE DE SÃO PEDRO: TRADE AND \\ PARISH OF SÃO PATRÍCIO DE ITAQUI (1850-1870)
}

\author{
Maria Medianeira Padoin* \\ Márcio Adriano de L. Rodrigues**
}

\begin{abstract}
Resumo: Este artigo analisa a organização da atividade mercantil que se estabelece na Província do Rio Grande de São Pedro, na segunda metade do século XIX, a partir da Paróquia de São Patrício de Itaqui, entre 1850 e 1870. Busca identificar como se manifestava a atividade mercantil em uma região de fronteira aberta e suscetível aos fluxos de artigos, pessoas e associações comerciais que se prolongavam ao longo do Rio Uruguai, colaborando para dinamizar a atuação dos comerciantes e negociantes nessa sociedade. Fontes primárias, jurídicas e administrativas, ajudaram a identificar por meio da pesquisa quantitativa um comércio que se prolongava graças à atuação de uma série de agentes e estratégias privadas de acumulação de recursos que se multiplicam nesse espaço fronteiriço, tornando possível a ampliação das atividades dos mais variados ramos de negócios. Assim, o comércio criou múltiplas estratégias nessa sociedade de fronteira favorável aos interesses mercantis que nos dispomos a analisar.
\end{abstract}

Palavras-chave: Comércio. Fronteira. Paróquia de São Patrício de Itaqui.

\footnotetext{
* Professora da Universidade Federal de Santa Maria (UFSM); Coordenadora do PPGH da UFSM; Coordenadora do Grupo de Pesquisa CNPq/UFSM História Platina: sociedade, poder e instituições; Coordenadora pelo Brasil do comitê de História, Região, Fronteira da Associação das Universidades do Grupo Montevidéu (AUGM).

E-mail:mmpadoin@gmail.com

** Mestre em História pela UFSM. Integrante do grupo de pesquisa em História Platina.

E-mail: sasrs@yahoo.com.br
} 


\begin{abstract}
This article analyzes the organization of business activity that is established in the Province of Rio Grande de São Pedro, in the second half of the nineteenth century, from the Parish of St. Patrick Itaqui, between 1850 and 1870. Seeks to identify as manifested commercial activities in a region bordering open and susceptible to the flow of goods, people and trade associations which went along the Rio Uruguay, helping to boost the performance of traders and dealers in this society. Primary sources, legal and administrative, helped identify through quantitative research a trade that went through the action of a number of agents and private strategies of accumulation of funds that multiply in this border area, making it possible to expand the activities of the various lines of business. Thus, trade has created multiple strategies that society border favorable to mercantile interests that we are willing to consider.
\end{abstract}

Keywords: Trade. Border. Parish of São Patrício de Itaqui.

\title{
INTRODUÇÃO
}

Este trabalho que tem como objetivo analisar a atividade mercantil que se desenvolvia na Paróquia de São Patrício de Itaqui, entre 1850 e 1870, surgiu da busca por delimitar as características das atividades econômicas desse mercado de caráter local, que se estabeleceu na Paróquia e conseguiu prolongar suas ligações para os territórios e mercados exteriores da Bacia Platina, envolvendo Buenos Aires, Montevidéu e espaços secundários localizados nas Províncias de Entre Ríos e Corrientes (Confederação Argentina), e ao Departamento de Salto, ligando-se ao "pueblo" de Constitución, no Estado Oriental.

Entre Ríos, Salto e os mercados secundários da Federación e Constitución se tornaram nesse contexto de dinamização de fluxos e contatos através do Rio Uruguai um empecilho à atuação dos grandes capitais ligados às burguesias dos portos principais da região, Buenos Aires e Montevidéu, graças à proliferação de fluxos lícitos e ilícitos de comércio praticado entre as diversas cidades e portos da região. ${ }^{2}$

Autores que tratam sobre esse espaço de fronteira, onde se integra Itaqui $^{3}$, identificaram como funcionava tão promissora atividade de comércio de caráter local, marcado pelo intenso fluxo mercantil promovido desde os contatos das cidades da fronteira oeste como Uruguaiana e Itaqui com o exterior.

Para caracterizar esse prodigioso comércio, foram utilizados dados de 2 semestres relacionados aos anos de 1860 e 1861, da Alfândega de Itaqui, abordando os movimentos de entrada e saída de mercadorias; 47 registros notariais do Tabelionato de Itaqui, 54 inventários Post-Mortem e 24 ações ordinárias cíveis e crime, que destacaram o caráter diferenciado dos fluxos ao longo do Rio Uruguai, destacando casas comerciais ligadas a vários ramos, envolvendo secos, molhados e secos e molhados, concessão de créditos e empréstimos, intermediação de negócios envolvendo casas, propriedades 
rurais ou barcos que se tornaram elementos determinantes para a reprodução das atividades mercantis desempenhadas na região.

As atividades de negociantes, portadores de grandes cabedais comerciais, também ajudaram a estabelecer uma noção de práticas diversas exercidas nesse ambiente mercantil, formando no espaço local atividades de comércio formadas a partir da diversificação das funções dos agentes ligados aos vários setores de atividades.

Nesse sentido, apresentamos este ensaio com o fim de discutir e demonstrar o quão é rico e complexo esse sistema de relações comerciais que se desenvolvia entre as cidades e portos da região de fronteira, permitindo a proliferação e reprodução das atividades dos negociantes, comerciantes e prestamistas locais ligados ao Estado Oriental, a Confederação Argentina e ao Império do Brasil.

\section{OS ESPAÇOS LIMÍTROFES: O RIO, A FRONTEIRA E A MOBILIZAÇÃO DOS FLUXOS}

A análise desse espaço mercantil de caráter local salientou a presença de novas formas de exploração econômica praticadas na região da Campanha, destacando o comércio como elemento dinamizador das relações nesse espaço local. Os fluxos através do Rio Uruguai e a presença da fronteira aberta permitiu o incremento de novas e variadas atividades de negócio nesse meio, como arrendamento de bens imóveis e semoventes, e a proliferação de atividades de beneficiamento de gêneros primários característicos da região como os couros e a erva-mate, beneficiando as atividades de produtores diretos ${ }^{4}$, nesses mercados.

Destaca-se nessa área limítrofe ao Rio Uruguai, a dificuldade de fiscalização e a presença do contrabando como aspectos promotores de novas atividades econômicas nesse meio, favorecendo a atuação de comerciantes e negociantes, desde portos secundários como Federación e Constitución, colaborando para escoar a produção da Paróquia, principalmente os couros beneficiados e a erva-mate, itens que se destacaram nas saídas das Listas da Alfândega local. ${ }^{5}$

Nesse meio algumas particularidades se salientam para torná-lo ainda mais apreciável a análise referente ao comércio, como a proximidade com as Províncias da Confederação Argentina e os Departamentos do Estado Oriental, centros consumidores de grande importância para os fluxos de gêneros como a erva-mate, que constituía grande parte dos gêneros de exportação que saiam através do porto de Itaqui, entre os anos de 1860 e $1861 .^{6}$

A presença desses portos, limítrofes ao Rio Uruguai, permitiu a formação e desenvolvimento de um amplo mercado consumidor que se estabelecia junto aos espaços platinos ampliando o número de agentes e fatores positivos 
ao incremento das atividades de comércio, como a instalação de estruturas produtivas nesses espaços, como a indústria de $\operatorname{couros}^{7}$ e outros itens como a erva-mate.

Assim, a presença do Rio Uruguai e de uma fronteira suscetível aos fluxos se associaram a localização da Paróquia, a frente de Corrientes, para promover o desenvolvimento de um circuito ampliado de gêneros que ganhavam os mercados da Confederação Argentina. ${ }^{8}$

O mercado que se formou compreendendo a região da Bacia Platina desde Itaqui, segundo a relação abaixo, obedecia a seguinte organização considerando destino, número de registros de entrada e saída de gêneros e tecnologias de transporte de itens mobilizáveis no meio.

Tabela 1 - Composição espacial do mercado que se prolongava ao longo do rio Uruguai (1860-1861)

\begin{tabular}{ccccc}
\hline $\begin{array}{c}\text { Cidade ou } \\
\text { Departamento }\end{array}$ & $\begin{array}{c}\text { Registros de } \\
\text { saída }\end{array}$ & Caráter & $\begin{array}{c}\text { Embarcações } \\
\text { rápidas }\end{array}$ & $\begin{array}{c}\text { Embarcações } \\
\text { rudimentares }\end{array}$ \\
\hline Federación & 19 & Longa & Chalupa & Lanchões \\
Constitución & 34 & Pequena & Vapor & Escuna \\
Restauração & 2 & NL & Chalupa & Lanchão \\
Salto & 2 & Longa & Escuna & Chalupa \\
Monte Caseros & 1 & Pequena & Palhabote & \\
Cruz & 1 & Pequena & Chalupa & \\
Concórdia & 0 & Longa & & \\
Santa Roza & 1 & Pequena & lanchão & \\
Passo de Itaqui & 0 & Pequena & & \\
\hline
\end{tabular}

Fonte: Elaboração própria. Mesa de Rendas de Itaqui. Listas de Alfândega. Dezembro de 1860 a maio de $1861 .{ }^{9}$

Todas essas articulações econômicas identificadas nas fontes primárias, que tratam da área, principalmente as relações de embarcações que saíam do porto de Itaqui, determinaram um mercado baseado na proliferação de companhias e associações familiares de estrangeiros, ocupando a maior parcela desses mercados.

Os Registros Notariais do Tabelionato de Itaqui e os Registros Paroquiais de Batismos da localidade se tornaram fontes vitais para determinar o caráter endógeno de atuação ligado a alguns agentes, identificados nas Listas de Alfândega. Os fluxos ampliados de novas tecnologias e artigos favoreceram a atuação de agentes que ligados a comerciantes e negociantes de vendas e lojas no interior da Paróquia conseguiam oferecer uma quantidade ampliada e variada de gêneros no mercado local, mantendo a oferta de artigos nos mercados interiores. 
Quando da análise dos Registros Notariais da Paróquia, se salientou a perfeita articulação dos interesses de capitais estrangeiros na manutenção desses fluxos, identificando uma série de associações se destacando no comércio de terras, prédios urbanos, concessão de empréstimos, créditos e fornecimento de gêneros, atuando graças à presença de alguns agentes.

A atuação direta das Associações Conceição \& Cia., de Montevidéu, Associação Dias de Freitas de Uruguaiana, a Associação Agostinho \& Cia., de Entre Ríos, aliadas a atuação das famílias Rodrigues, Canepa, Veppo, José Marcenaro, Emigdio Bonorino, Pedro Larabure e Jorge Tripowich estabeleceu uma perfeita articulação entre as atividades no interior da Paróquia e os fluxos de bens e capitais que se desenvolviam no circuito mercantil formado entre portos e cidades ao longo do Rio Uruguai. ${ }^{10}$

A metodologia empregada, baseada no entrecruzamento entre variadas tipologias de fontes e a identificação nominal dos agentes, identificou uma mercancia que se estendia rio abaixo ${ }^{11}$, chegando até as portas do Atlântico e um contrafluxo de artigos, gêneros, pessoas e capitais, que se aproveitavam das ligações permitidas pelo Rio Uruguai para reproduzir riquezas, poder e status nas várias povoações que podiam contar com um porto.

Itaqui mantinha, nessa dinâmica, relações com o porto da Federación, Concórdia, Monte Caseros e Constitución em ambos os lados do Rio Uruguai. Dessa atuação sujeitos como Manoel Marenco ${ }^{12}$, conseguiam manter negócios entre ambos os espaços, e reproduzir interesses de agentes e associações estrangeiras nos mercados que se multiplicavam na Paróquia. 


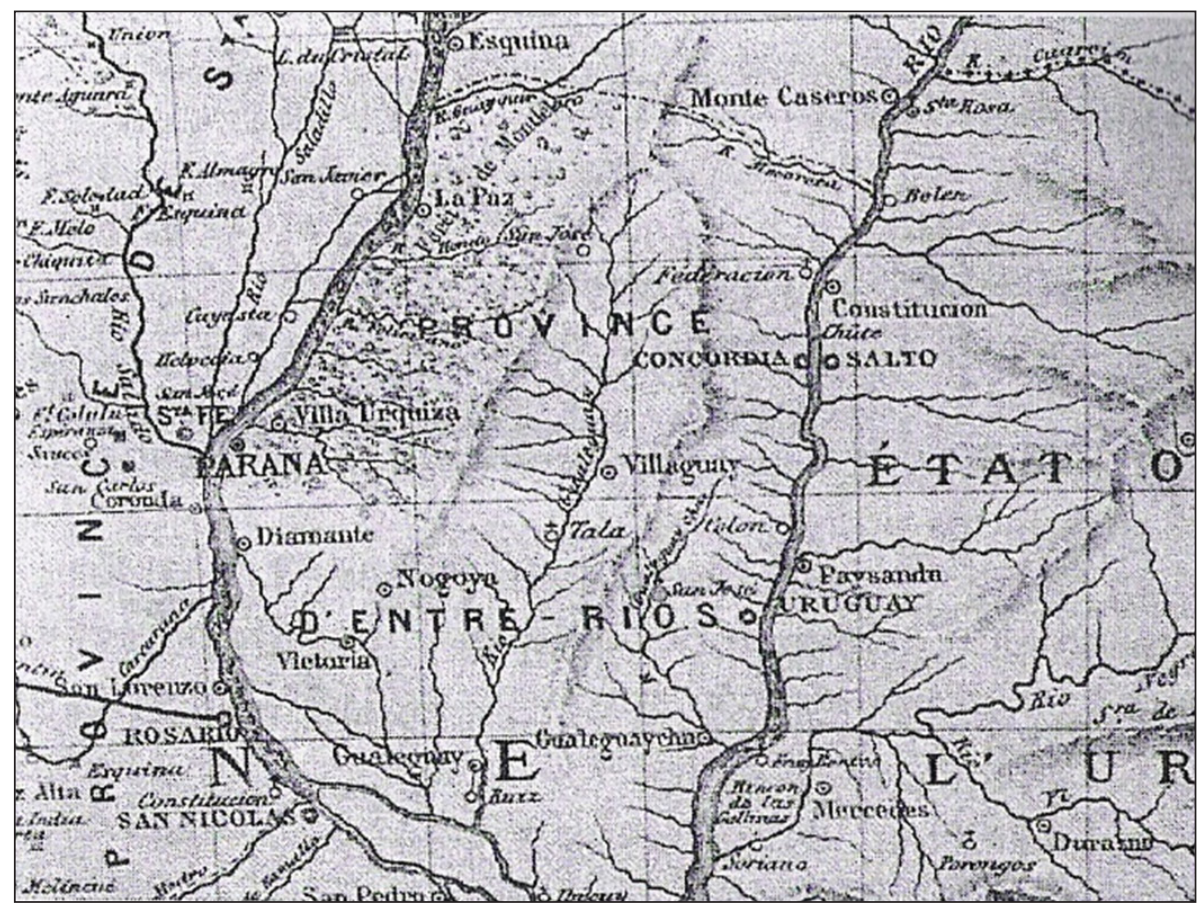

Figura 1 - Mercados e rotas no estuário do PrataFonte. Fonte: Mapa baseado em SCHMIT, Roberto. Historia del capitalismo agrario pampeano. Los límites del progreso: expansión rural em los orígenes del capitalismo rioplatense. Entre Ríos 1852-1872. Buenos Aires: Siglo XXI, 2008. p. 45.

Logo, a partir do intenso fluxo de embarcações permitidos pela presença do rio, e contando com as oportunidades que surgem diante do caráter de intensa circularidade da região de fronteira, penetravam na Paróquia diversas famílias e agentes nacionais ou estrangeiros, que agindo individualmente ou em grupos, se introduziram nas práticas de comércio de recursos como terras, gados, capitais e créditos, atuando sob a forma de associações e companhias desde centros como Salto, Montevidéu, Porto Alegre ${ }^{13}$ e Entre Ríos.

Das Listas de Alfândega quando identificadas algumas referências nominais de agentes que efetivavam fluxos de erva-mate, couros, tamancos e graxas desde o Rio Uruguai, localizamos: 64 saídas de embarcações e aproximadamente 7 agentes, que atuavam na Paróquia e nos fluxos através do Rio Uruguai, atestando a ligação estreita entre os fluxos externos e os movimentos do comércio endógeno praticado na Paróquia.

Logo, José Marcenaro, Pedro Larabure, Gil Rodrigues, Luis Canepa, Jorge Tripowich e Emigdio Bonorino promoveram a interlocução da Paróquia aos circuitos mercantis da região se utilizando de laços de clientela, compadrio e vizinhança, para colocar a disposição nas casas de comércio local, artigos e gêneros importados de outros centros, dinamizando as relações comerciais 
locais dessa cidade que podia contar com um porto favorável a entrada de gêneros. ${ }^{14}$

Ao serem intercalados esses sujeitos nominalmente, e relacionados com os Inventários Post-Mortem de comerciantes de Itaqui, percebeu-se que eles eram residentes ou ligados a lojas ou vendas no interior da Paróquia, sendo que oito das maiores casas de negócio da localidade, as casas de comércio de José Antônio Figueira, João Rivaldo e Vicente Marisco, entre outras, tinham algum tipo de ligação com esses agentes que atuavam nos fluxos fluviais de comércio praticados através do Rio Uruguai.

Dessa relação partimos para a definição do que se denominou na pesquisa de caráter endógeno de atuação. Esse conceito define a quantidade de ligações que se mantinham desde agentes que atuavam nos fluxos através do Rio Uruguai e efetuavam seus negócios com comerciantes no interior da Paróquia. Tornar-se-ia vital essa articulação para a entrada de gêneros finos e manufaturados no mercado nacional, carente de produções de gêneros de luxo e manufaturados, que exigiam um maior grau de sofisticação.

\section{Gráfico 1 - Relação de agentes do comércio fluvial ligados direta ou indiretamente ao comércio endógeno da paróquia ${ }^{15}$}

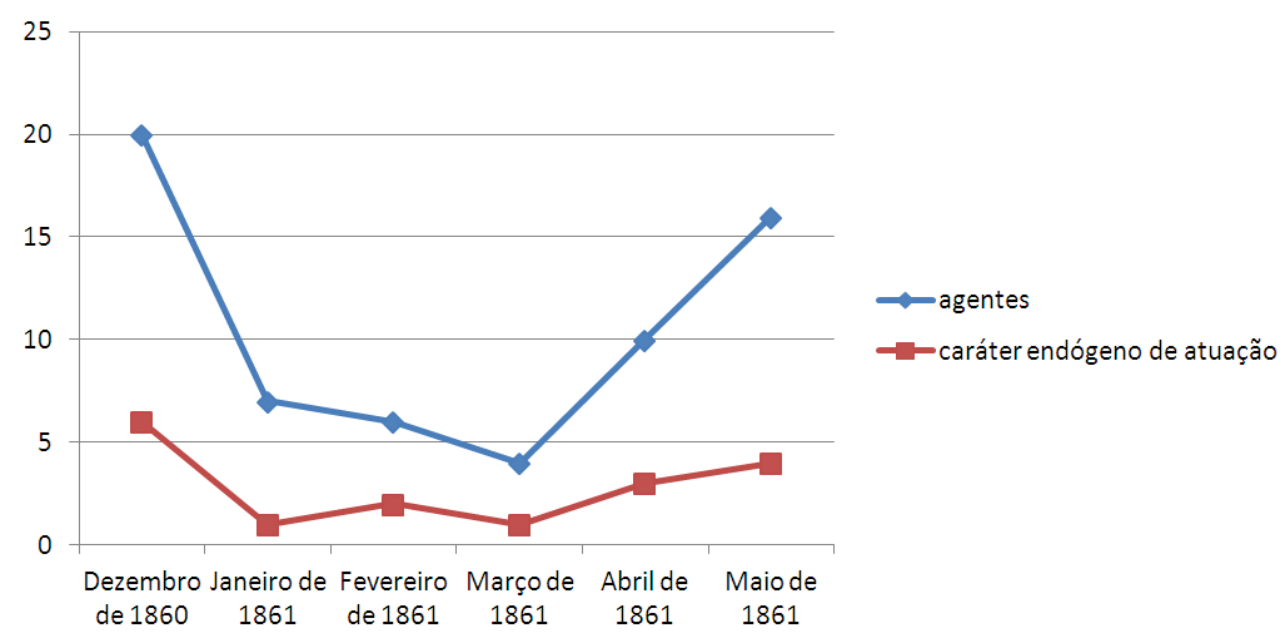

Fonte: Elaboração Própria. Listas de Alfândega. Mesa de Rendas de Itaqui. Dezembro de 1860 a maio de $1861 .{ }^{16}$

A identificação do "nome" do mestre negociante que possuía embarcação atuando nesses mercados, principalmente nos Registros Paroquiais de Batismos, ao articular-se com as Listas de Alfândega, ajudou a caracterizar a ligação entre os fluxos de um comércio interno e os movimentos do comércio fluvial que se efetivava desde Itaqui ligando-se às províncias limítrofes do outro lado do Rio Uruguai. 
A presença de muitos estrangeiros, outro fator de destaque nesses mercados, apoiava-se na atuação de residentes em Itaqui, como José Marcenaro, que se utilizando de práticas costumeiras e tecnologias rudimentares conseguiu manter os fluxos de um pequeno comércio, contando com a atuação de sua chalupa. A melhoria tecnológica e os intensos investimentos de capitais nos fluxos criaram na região mercados restritos e outros mais ampliados, como pode se ver na relação seguinte:

Tabela 2 - Mercado de caráter local - 1861 ${ }^{17}$

\begin{tabular}{cccccc}
\hline Período & Mercado & Atuação & $\begin{array}{c}\text { Agentes de } \\
\text { destaque }\end{array}$ & $\begin{array}{c}\text { Variação de } \\
\text { transportes }\end{array}$ & Saídas \\
\hline Dezembro de 1860 & Santa Roza & Local & José Marcenaro & Chalupas & 2 \\
Janeiro de 1861 & Restauración & Local & José Marcenaro & Chalupas & 2 \\
Fevereiro de 1861 & Restauración & Local & Família Rodrigues & Chalupas & 2 \\
Março de 1861 & Federación & Local & José Marcenaro & Chalupa & 4 \\
Abril de 1861 & Federación & Local & José Vinhas & Chalupa & 5 \\
Maio de 1861 & Povo da Cruz & Local & Família Rodrigues & Chalupa & 2 \\
\hline
\end{tabular}

Fonte: elaboração própria. Listas de Alfândega. Mesa de Rendas de Itaqui. Dezembro de 1860 a Maio de 1861.

A complexidade desses mercados revelou algumas particularidades, ligadas, sobretudo a natureza das embarcações e ao destino dos agentes quando atuando ao longo do Rio Uruguai. Quando esse mercado se ampliava era resultado da atuação de organizações famílias ou mesmo da introdução de alguma inovação nesses mercados, como o vapor "Uruguai", de Antonio Eugênio de Freitas Guimarães que absorvia grande parcela desses fluxos.

A presença de tais elementos de distinção, novas tecnologias de transporte e a atuação de associações, criaram mercados mais seletivos, levando a eliminação de muitos nacionais nos registros dos autos. A proliferação de agentes e a introdução de novas práticas e tecnologias destacou a presença de centros mais complexos de atividades como o "pueblo" da Constitución e a sub-coletoria de Salto. ${ }^{18}$

Mercado dominado por estrangeiros, como os correntinos da família Rodrigues, Constitución promoveu a incorporação e ampliação de novos circuitos mercantis na região interligando Itaqui as Províncias da Confederação Argentina, segundo a relação abaixo: 
Tabela 3 - Incorporação do mercado da constitución aos fluxos

\begin{tabular}{|c|c|c|c|c|c|}
\hline Período & Mercado & Atuação & Agentes de destaque & $\begin{array}{l}\text { Variação de } \\
\text { transportes }\end{array}$ & Saídas \\
\hline $\begin{array}{c}\text { Dezembro de } \\
1860\end{array}$ & Constitución & Longa & $\begin{array}{l}\text { Antônio Eugênio de } \\
\text { Freitas Guimarães }\end{array}$ & Vapor & 15 \\
\hline $\begin{array}{c}\text { Janeiro de } \\
1861\end{array}$ & Constitución & Longa & $\mathrm{X}$ & $\mathrm{X}$ & 2 \\
\hline $\begin{array}{c}\text { Fevereiro de } \\
1861\end{array}$ & Constitución & Longa & Gil Rodrigues & Chalupa & 1 \\
\hline $\begin{array}{l}\text { Março de } \\
1861\end{array}$ & Constitución & $\mathrm{X}$ & $X$ & $X$ & 0 \\
\hline $\begin{array}{c}\text { Abril de } \\
1861\end{array}$ & Constitución & Longa & José Marcenaro & Chalupa & 5 \\
\hline $\begin{array}{c}\text { Maio de } \\
1861\end{array}$ & Constitución & Longa & $\begin{array}{l}\text { Antônio Eugênio de } \\
\text { Freitas Guimarães }\end{array}$ & Vapor & 11 \\
\hline
\end{tabular}

Fonte: elaboração própria. Listas de Alfândega. Mesa de Rendas de Itaqui. Dezembro de 1860 a maio de 1861.

Mantinham os contatos entre Constituición-Itaqui-Confederación, José Marcenaro, e a família Rodrigues, promovendo a entrada de artigos provenientes de Montevidéu nas Províncias do interior da Confederação Argentina, promovendo a interferência no comércio de monopólios praticado desde Buenos Aires nesses espaços, pela atuação de comerciantes desde Itaqui e Salto.

Esse fenômeno, de modernização de fluxos a partir de estrangeiros e associações, se confirmou quando as Listas de Notários ${ }^{19}$ e as Procurações ${ }^{20}$ salientaram uma penetração maciça de organizações, associações e redes familiares operando na Paróquia e se salientando ao longo das atividades econômicas ligadas ao comércio de terras, créditos, gados e artigos manufaturados. Destacaram-se na constituição dessas redes, além da Associação Almeida e Silveira de Entre Ríos ${ }^{21}$, outros grupos e organizações, segundo a seguinte relação: 
Tabela 4 - Agentes mercantis atuando no espaço da paróquia

\begin{tabular}{ccccc}
\hline Agentes & Idade & Nacionalidade & Atuação & Auto \\
\hline $\begin{array}{c}\text { Manoel Marenco representante } \\
\text { da Conceição \& Cia. }\end{array}$ & 33 & $\begin{array}{c}\text { Oriental } \\
\text { Montevidéu } \\
\text { Dias de Freitas e Cia }\end{array}$ & $\begin{array}{c}\text { Associação } \\
\text { estrangeira }\end{array}$ & LNTI 3 \\
& & $\begin{array}{c}\text { Saltino } \\
\text { Salto }\end{array}$ & Associação & LNTI 8B \\
Agostinho Silveira e Cia. & $\begin{array}{c}\text { Concórdia/ } \\
\text { Entre Ríos }\end{array}$ & Associação & LNTI 2 \\
Kasten \& Cia. & Uruguayana & & LNTI 2 $^{\text {a }}$ \\
\hline
\end{tabular}

Fonte: Elaboração Própria. Registros Notariais do Tabelionato de Itaqui. APERGS. Porto Alegre. 1863-1875. LNTI 2A (1863-1870), 8B (1870-1872), 3 (1872-1875). APERGS. Porto Alegre. ${ }^{22}$

\section{A PARÓQUIA DE ITAQUI, O CONTEXTO LOCAL E A CARACTERIZAÇÃO DO MERCADO INTERNO}

A Paróquia de São Patrício de Itaqui, localizada às margens do Rio Uruguai ${ }^{23}$ à frente da cidade de Alvear, Província de Corrientes, na Confederação Argentina, a partir de 1850 passou a ser influenciada por uma série de elementos, como a proliferação de redes e dos fluxos de comércio que se efetivaram com as áreas limítrofes.

A permanência de algumas culturas de produção nativas como a ervamate, e o manejo e comercialização do gado e seus derivados permitiu a proliferação dos fluxos de comércio local, indo de encontro ao que se refere Avé-Lallemant ${ }^{24}$, naturalista francês, quando determina que a articulação de Itaqui aos fluxos de um comércio regional se fazia graças à intensa circularidade permitida pelo Rio Uruguai.

Nesse contexto ocorre a confirmação do rio, como opção aos fluxos de pessoas e artigos que se estabeleciam nessa área ${ }^{25}$, interligado os vários portos, aos mercados da Federación, Constitución, Restauración, Salto e Monte Caseros, cidades que possuíam portos ou se articulavam aos movimentos de comércio, em ambos os lados do Rio Uruguai. ${ }^{26}$

Logo, os rios (Ibicuí, Quaraí, Uruguai e os demais rios que deságuam na bacia Platina), possibilitaram a ampliação do campo de atuação aos agentes e as sociedades mercantis às margens do Rio Uruguai, mediante o comércio de artigos diversos, com destaque para a "herva-mate", fumo, arroz, "bolaxas" e aguardente. ${ }^{27}$

Os contatos dos comerciantes com os fluxos através do Rio Uruguai e a atuação das associações promoveram a criação de um mercado complexo, 
onde os negociantes podiam atuar com uma gama diversificada de artigos envolvendo secos e molhados vendidos no atacado e também no varejo.

$O$ relato sobre gêneros de algumas casas comerciais ajudam a compreender os itens que constituíam tal comércio e os agentes que se salientaram ao longo dos fluxos e atividades mercantis como José Tossi ${ }^{28}$, italiano, dedicado a um ramo de negócio, que envolvia grandes quantidades de gêneros, caracterizando as ligações pertencentes ao setor de atacado. Esse agente atuava no ramo de secos e molhados, fornecendo os gêneros no atacado a outros agentes, pela quantidade de alguns artigos que se refere o auto jurídico.

Vendia em sua casa de comércio garrafões de anis, garrafões de ginelma, caixas de sabão, caixas de polvilho, peixes fau, caixão de fideus, sacos de bolachas, sal, amendoim, azeite doce, açúcar, sacos de feijão e farinha de trigo, sempre em grandes quantidades, a outros comerciantes.

Outro italiano que se destacou nesse espaço local foi João Rivaldo, ligado ao atacado de têxteis. Destacam-se no auto desse agente camisas de Gênova (30 un.), camisas brancas (84 un.), camisas brancas de peito (30 un.), 1 alqueire de farinha, 1 caixa de conhaque Martel, e vinhos da marca Carlon, caracterizando um atacado de secos e molhados marcada pela grande diversidade de itens.

Entre os portugueses que exerciam atividades de comércio na área identificou-se um agente ligado ao comércio de secos e molhados, executado a base de tecidos, roupas feitas, alimentos, perfumes, ou seja, artigos diversos. Todos esses artigos eram comercializados na casa comercial de José Antonio Figueira. ${ }^{29}$

Ainda se destacou Figueira através da venda a comerciantes menores, de caixas de agulhas, alfinetes, dedais, botões (sempre em grandes quantias) vendidos no atacado. Nas bebidas seriam 120 medidas de aguardente, e 120 medidas de vinho, e outros muitos gêneros como 30 panelas de ferro e 1 dúzia e meia de colheres de metal.

A atuação desses agentes ajudou a caracterizar um comércio de grandes redes de ligações que os comerciantes mantinham por meio de dívidas ativas e passivas, e sua relação íntima com associações e estrangeiros que apoiavam os fluxos de créditos e artigos específicos, os têxteis e manufaturados diversos. 
Tabela 5 - Comparação entre ativos de alguns agentes mercantis

\begin{tabular}{cccc}
\hline & $\begin{array}{c}\text { Rivaldo } \\
\text { (comerciante - italiano) }\end{array}$ & $\begin{array}{c}\text { Figueira } \\
\text { (comerciante - português) }\end{array}$ & $\begin{array}{c}\text { Paulo Moura } \\
\text { (negociante - brasileiro) }\end{array}$ \\
\hline Ativas & 61 & 6 & 39 \\
Passivas & 10 & 40 & 6 \\
\hline Total & 71 & 46 & 45 \\
\hline Associações & 3 & 2 & 3 \\
Estrangeiros & 6 & 8 & 1 \\
\hline $\begin{array}{l}\text { Fonte: Elaboração Própria. Inventários Post-Mortem de Itaqui. APERGS. Porto Alegre. Auto: 231, } \\
\text { 186, 191, 256 maço: 8, 6, 5, 9. Ano: 1874, 1870, 1864, 1876. }\end{array}$
\end{tabular}

Essa amostra caracterizou a atuação de agentes pequenos e grandes, pela quantia de dividas ativas e passivas que podiam manter, onde os menores possuíam um grande número de dívidas ativas, vendendo a consumidores apenas.

Comerciantes e negociantes maiores, possuíam um maior número de dívidas passivas, em geral ligadas a outros comerciantes, destacando a atuação de agentes como Paulo Moura ou José Antônio Figueira. Rivaldo, por desempenhar atividades de uma venda, ao contrário das lojas de seus concorrentes, vendia poucos artigos a crédito, ligando-se a um único ramo de gêneros, os alimentos vendidos a consumidores que não exerciam de forma específica atividades de comércio.

\section{CONSIDERAÇÕES FINAIS}

A relação de dados acerca da atividade comercial exercida na Paróquia de São Patrício de Itaqui, baseados em fontes de caráter primário, administrativas e jurídicas, identificou um conjunto de relações que se exercem junto à Paróquia, marcadas pela forte presença de estrangeiros, exercendo atividades desde os fluxos ligados ao Rio Uruguai até penetrarem no mercado interno de Itaqui, fornecendo gêneros a proprietários de vendas e lojas.

Logo, no setor mercantil, platinos e europeus se dedicavam às mais diversas atividades, atuando como fornecedores de gêneros, como João Cerro, saltino, em sua ligação com João Armand Mousquere, comerciante francês, sediado na Paróquia, ou as diversas companhias que se multiplicavam desde Entre Ríos, como Agostinho Silveira \& Cia., oferecendo novas opções econômicas e formas de atuar nesses espaços mais favoráveis ao capital mercantil.

Assim, junto às atividades de companhias estrangeiras, associações e redes familiares que detêm parcela significante dos fluxos e mercados regionais, 
já ocorre a presença de nacionais ocupando posições de destaque ao longo das atividades mercantis. Esses negociantes atuavam em uma grande diversidade de campos de atuação, onde figuram homens como Emigdio Bonorino, nacional, que se dedicava a sua botica, atuando como fármaco, juiz e negociante, ligandose também aos fluxos através do Rio Uruguai.

Esse personagem, em particular, revela uma das alternativas utilizadas pelos grupos mercantis para atuar diante dos recursos fechados ${ }^{30}$, que permaneciam nas mãos de estancieiros. Visando oportunizar novas formas de auferir riquezas, posição e status a partir da intermediação dos fluxos permitidos pela fronteira, os comerciantes conseguiam galgar posições e diversificar o ambiente local se dedicando as atividades de trocas.

Nesses espaços além das condicionantes políticas, as migrações das províncias limítrofes da Confederação Argentina, Corrientes e Entre Ríos e os franceses que viriam do Estado Oriental contribuíram para dinamizar as atividades econômicas, a partir do incremento de novas práticas e tecnologias que criaram hierarquizações nas atividades e na própria sociedade das povoações limítrofes ao Rio Uruguai.

A posição geográfica, próxima das Províncias de Corrientes e Entre Ríos, possibilitou a Itaqui, situada às margens do Rio Uruguai, se aproveitar da presença da via fluvial de comunicação para favorecer o incremento dos fluxos e redes que se destinam quase que em sua maioria para Entre Ríos, Concórdia, Monte Caseros e Federación.

A presença das atividades de comércio ampliou o campo de atuação às populações fronteiriças, aliando aos fluxos através do Rio Uruguai, economias de caráter natural, de extração, além de um artesanato especializado e uma manufatura de importados.

Ao que tudo indica o comércio e a intermediação (prestação de serviços) nesse ambiente complexo que se faz junto à fronteira, assumia as mais diversas formas, compra e venda de artigos, fabrico e venda de embarcações, terras, casas, propriedades e escravos. Os serviços de prestamistas, transportadores, carreteiros e fornecedores surgiram como novas opções para as populações de europeus e platinos que circulavam na área.

Portanto, o Rio Uruguai, através de seus fluxos, permitiu uma reorganização das atividades mercantis que se multiplicaram nos portos e na Paróquia se São Patrício de Itaqui, onde os comerciantes e negociantes eram obrigados para se manter nos mercados, segundo práticas diferenciadas, objetivando incrementar estratégias ampliadas para acessar os recursos, mobilizar capitais e arregimentar novos instrumentos como fizera José Marcenaro ao comprar duas embarcações para atuar nos fluxos desde Itaqui, prolongando seus negócios até Uruguaiana.

A utilização do espaço de fronteira, as inúmeras motivações política e a intensa circularidade na área, salientou o surgimento de um espaço diverso, 
orientado segundo a diversificação e interação das atividades das diversas etnias, indivíduos e em busca de ampliar suas capacidades no espaço de exploração econômica. A proliferação de instrumentos, capitais e oportunidades mobilizou novas práticas, costumes, estratégias por parte dos vários agentes objetivando manter seus negócios de forma mais favorável nesses mercados.

\section{NOTAS}

1 Pesquisa financiada pela CAPES, bolsa DS.

2 RODRIGUES, M. A. O comércio na Paróquia de São Patrício de Itaqui nas décadas de 60 e 70 do século XIX. Trabalho de Conclusão (Graduação em História), UNIFRA, Santa Maria, 2006. O autor localizou em seu trabalho a articulação da Paróquia aos portos descritos nas obras de Schmit (2008) e Chiaramonte (1991).

3 Autores como Foletto (2003), Colvero (2004) Thompson Flores (2006) e Schmit (2008) destacam o caráter de complementaridade das atividades de comércio ligadas as cidades localizadas na região platina, ao envolver os portos brasileiros, do Estado Oriental e da Confederação Argentina.

${ }^{4}$ Nível de atividades em que o produtor direto do gênero, leva-o ao mercado onde se dá sua comercialização.

${ }^{5}$ Referente aos couros, Silvério Piagetti, italiano, possuía na Paróquia um curtume identificado no inventário Post-Mortem n. 402, maço 15, ano de 1887, localizado no APERGS, Porto Alegre. Já quanto ao beneficiamento de erva-mate, foi identificado o estabelecimento de Paulo José Dutrey, um francês, dedicado ao beneficiamento desse gênero, promovendo ligações com muitos carreteiros, dentre os quais Lamoyson, identificados no auto: 390, maço $16 \mathrm{~A}$, ano 1862, localizado no APERGS em Porto Alegre. Essa relação mostra a importância dos estrangeiros na constituição e modernização das atividades nesse espaço local, ao formar atividades e economias de escala no espaço onde desenvolviam suas atividades.

${ }^{6}$ O caráter limitado dos registros deve-se ao fato da não localização de fontes referentes à Itaqui nos arquivos, onde a maioria da tipologia de documentos estava ligada a cidade de Uruguaiana. Nosso trabalho as utilizou para identificar agentes que atuavam nos dois espaços, da Província e no exterior, sendo por isso considerado apenas esse período de dois anos, visando localizar de forma específica alguns agentes que formavam os fluxos.

7 Inventários Post-Mortem. Auto: 402. Maço: 15. Ano: 1887. APERGS. Porto Alegre.

${ }^{8}$ FOLETTO, Arlene, Guimarães. Dos campos junto ao Uruguai aos matos em cima da serra: a paisagem agrária na Paróquia de São Patrício de Itaqui (1850-1889). Dissertação (Mestrado em História), UFRGS, Porto Alegre, 2003.

9 A denominação Longa designa mercados de longa distância onde proliferava a atuação de companhias estrangeiras na sua maioria ligadas ao porto da Constitución. A designação "Pequena" são mercados de amplitude local, rudimentares e utilizados em sua maioria pelas embarcações de habitantes da Paróquia. Nesses mercados lanchões, palhabotes e chalupas, rudimentares são ligados ao fluxo local que compreende Cruz, Federación, Monte Caseros. Vapores e Escunas, mais rápidos e com maior tonelagem destinam-se na sua maioria a Salto e ao pueblo da Constitución. 
${ }^{10}$ Listas de Alfândega de Itaqui. Relação de Passes Expedidos entre Dezembro de 1860 a Maio de 1861. AHERGS. Porto Alegre.

${ }^{11}$ SCHMIT, Roberto. Historia del capitalismo agrário pampeano. Los Límites del progreso: expansión rural em los orígenes del capitalismo rioplatense. Entre Ríos 1852-1872. Buenos Aires: Siglo XXI, 2008.

${ }^{12}$ Registros Notariais do Tabelionato de Itaqui. APERGS. Porto Alegre. Livro 3 (1872-1875). APERGS. Porto Alegre

${ }^{13}$ Procurações. APERGS. Porto Alegre. 23 nov. 1874 a 11 fev. 1876. 24 procurações. Livro 3c. 2 jun. 1875 e 11 fev. 1876. Relações de dívida e créditos mantidas desde Itaqui por Manoel Vicente de Menezes e Manoel Silvério Gomes com Joaquim Alves Leite (negociante) e Associação de comerciantes (Paranho e Castilho).

${ }^{14}$ Para Figueiredo (2012) a região de fronteira oeste mobilizou atividades de criação e extração que ampliaram recursos determinantes para promover a reorganização e circulação entre mercados ampliados, onde o comércio assumiria o papel de incorporar as novas populações às matrizes econômicas da região, a erva-mate e o gado e seus derivados aos vastos fluxos que compreendiam Itaqui-Alvear-Salto e Restauración.

${ }^{15}$ Em dezembro de 1860 mantém ligações em ambos os lados do Rio Uruguai: Jorge Tripowich, Gil Rodrigues, Luis Canepa, João Batista Veppo, Julio Veppo e Francisco Rodrigues. Janeiro de 1861: José Marcenaro; Fevereiro de 1861: Gil Rodrigues, Francisco Rodrigues e José Vinhas; março de 1861, atuava José Marcenaro; em abril de 1861: José Marcenaro, Julio e João Batista Veppo, José Vinhas (duas vezes) e maio de 1861 seriam Gil Rodrigues, Luiz Canepa, Pedro Larabure, José Rodrigues e Jorge Tripowich que atuariam em ambos os espaços, no Rio Uruguai, ligando-se a comerciantes e fluxos desenvolvidos no interior da Paróquia.

${ }^{16}$ Jorge Tripowich seria registrado em um batismo, identificado no Livro de Batismos. $n$. 1B. Itaqui. Ano: 1859. IJCSUD. Luiz Canepa foi identificado como credor de José Antônio Figueira. Esse agente é ligado ao mercado da Constitución. José Marcenaro foi identificado na atuação contra a Alfândega de Uruguaiana, referente a cobrança de impostos concernentes a um lanchão, naquele porto. Livro 8B. APERGS. Porto Alegre - 1870-1872. Os Veppo são registrados morando e batizando em Itaqui, em 9 jan. 1878 e 19 jan. 1878 Luiz e Romalina Livro de Batismos. n. 3B. Itaqui. Ano: 1873-1879. IJCSUD.

${ }^{17}$ Mercados de Cruz, Monte Caseros, Restaurción e Federación nas proximidades da Paróquia dedicados a pequenas embarcações que se empregavam nos fluxos do comércio fluvial, utilizadas por alguns habitantes de Itaqui, como José Marcenaro.

${ }^{18}$ ABADIE, Washinton Reyes; ROMERO, Andrés Vazquez. Crónica general del Uruguay. Montevideo: Ediciones de La Banda Oriental, 2000.

${ }^{19}$ Registros Notariais do Tabelionato de Itaqui. APERGS. Porto Alegre. 1863-1875. LNTI 2A (1863-1870), 8B (1870-1872), 3 (1872-1875). APERGS. Porto Alegre.

${ }^{20}$ São 24 registros de ligações para fora da Paróquia, onde 7, ou seja, 29\% da amostra entre 1874 e 1876. Das 24 relações 41,6\% são relativas ao comércio de artigos e 33,3\% são refrentes a bens rurais.

${ }^{21}$ Identificada nos inventários de Antonio Eugênio Figueira. Inventários Post-Mortem. Órfãos e Ausentes. Auto: 186, maço: 6, ano: 1870. APERGS. Porto Alegre.

${ }^{22}$ Haveria uma Associação Dias de Freitas ligada a Uruguaiana e localizada no auto: 186, maço: 6, ano: 1870. Cartório de Órfãos e Ausentes de Itaqui. APERGS. Porto Alegre. 
${ }^{23}$ FOLETTO, op. cit.

${ }^{24}$ AVÉ-LALLEMANT, Robert. Viagem pela provincia do Rio Grande do Sul (1858). Belo Horizonte: Ed. Itatiaia; São Paulo: Ed. Universidade de São Paulo, 1980.

${ }^{25}$ COLVERO, Ronaldo. Negócios na madrugada: o comércio ilícito na fronteira do Rio Grande do Sul. Passo Fundo: UPF, 2004.

${ }^{26}$ Nessa dinâmica, segundo Colvero (2004) foi à ampliação de populações e o grande afluxo de estrangeiros, exercendo atividades de comércio, que levaram a instalação do porto na cidade, em 1853.

${ }^{27}$ Mapa demonstrativo de gêneros exportáveis pela Mesa de Rendas de Itaqui no $2^{\circ}$ semestre de exercício 1857-1858. Junho de 1858. RODRIGUES, op. cit.

${ }^{28}$ Ações Ordinárias Cíveis e Crime. Auto: 384, maço: 16 A, ano: 1859. APERGS. Porto Alegre. A atividade do setor atacadista caracterizava-se por manter um número limitado de ligações desde seus promotores, o que discernia um espaço restrito de relações a seus agentes, e, portanto, um número menor de estratégias que poderiam ser mantidas. Um número ampliado de estratégias significava manter uma base favorável às alianças com outros grupos e famílias.

${ }^{29}$ Inventários Post-Mortem. APERGS. Cartório de Órfãos e Ausentes. Porto Alegre. Auto: 186, maço: 6, ano: 1870 .

${ }^{30}$ Referência ao monopólio da terra aos grandes estancieiros a partir da Lei de Terras de 1850 e a atividade de criação, e extração de charque, couros que estava nas mãos de estancieiros.

Artigo recebido em outubro de 2011. Aceito em setembro de 2012. 